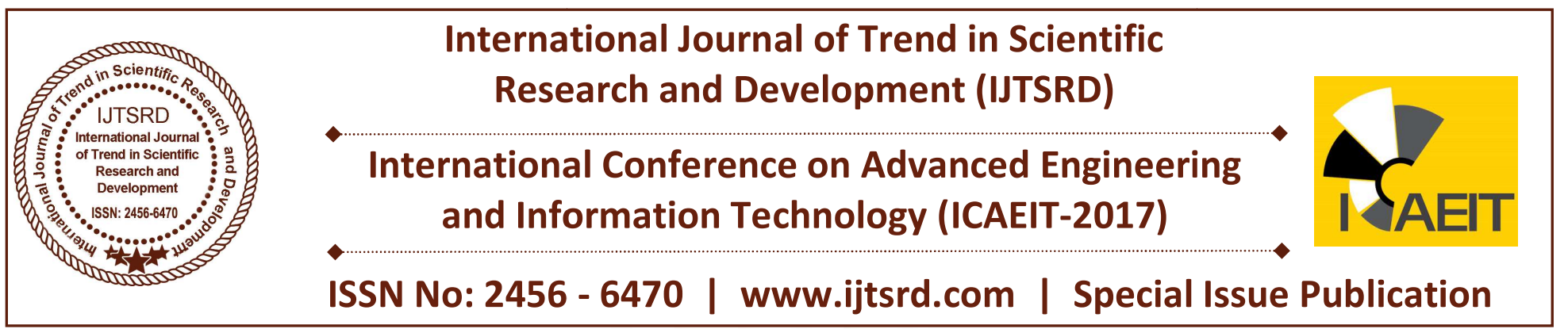

\title{
Business Intelligence for Small-Scale IT-Based Entrepreneurship in Malaysia
}

\author{
Alinaswe Sikana ${ }^{1}$, Amanda Percy Kinsi ${ }^{1}$, Mia Torres-Dela Cruz ${ }^{2}$, Illiana Azizan ${ }^{2}$ \\ ${ }^{1}$ Linton University College, Negeri Sembilan, Malaysia \\ ${ }^{2}$ Department of Engineering and Technology, Linton University College, Negeri Sembilan, Malaysia
}

\begin{abstract}
Small-scale businesses are the heart of Malaysian economy. It is but proper to support these businesses with new technology for their information needs. One such technology is business intelligence. Although it was developed with large businesses in mind, new processes in data management has made things possible for small business to use this technology. Small IT-based entrepreneurship in Malaysia may yet to benefit from the use of business intelligence in managing information in their organizations. The paper is an exploratory study to apply business intelligence in small-scale IT-based business processes to get the maximum benefit from large amount of data for informed decision making.
\end{abstract}

\section{Keywords: Business Intelligence, IT-based} entrepreneurship, Small Scale Businesses

\section{Introduction}

It is undeniable that small-scale businesses in Malaysia render an important role in the country's economy. The demand for information to be used in business has increased in the last few years. Even small-scale enterprises demand for large volumes of information in order to be competitive. Because of this, business intelligence $(\mathrm{BI})$ will play a big role [1]. Initially, BI was developed for large enterprises because of their requirements for large volumes of information and the cost of processing and extraction of relevant information from big data. But small or large, enterprises need to improve their processes to progress and take their niche in the business world.
Business intelligence is a term that surfaces when 'Data' and 'Business' collide. When a business is utilized to provide competition in the market or gain market dominance, it should know how to strategically use that data by knowing how to collect it and process the data. BI (Business Intelligence) is integrated into a business as a system (BI System). BI systems aim to combine the work flow by assisting the upper management in making executive decisions.

The data that is used in the system comes in two forms-'External' and 'Internal'. Internal data is that which is collected from within the business and external is from outside. The information gained from the data also helps to optimize workflow.

When it comes to BI in small businesses, it is a completely different figure. Unlike the giants of the market, small businesses don't have the adequate resources. When small businesses venture into acquiring a BI System, they often go in with halfbaked minds.

They want to "Future Proof" their system. They wish to begin with a system that can do it all from the getgo. Some of the reasons as to why it is difficult for small businesses to acquire BI System are:

\section{$>$ Limited Capital \\ $>$ Limited Personal}

BI System providers make it seem like getting hold of a system is a seamless task yet it is rather overwhelming. For a business that uses stand-alone computers, the analytics tools have to be installed 
locally on each machine and in such a situation sharing of information and formulation of required reports would require extra coordination.

The objective of this paper is to provide a proper understanding of how BI system can be acquired on a budget and integrate them in a small or medium sized business in Malaysia. Not only acquiring the BI system but how to efficiently make use of it. E.g., instead of getting a full-fledged system from the getgo, just acquire a system that meets the current needs and leave room for upgrades for future requirements.

\section{Business Intelligence}

Many authors have defined BI according to their context. BI is a tool that helps organizations improve decision making by tracking, processing, storing and analyzing data and transforming it into insights. Business users can in turn use these insights to make the right decisions in the right time, cutting costs, identifying new business opportunities and improving their organization's performance [2].

Chaudhuri and Narasayya [3] defined business intelligence as a group of technologies for decision support specifically for the enterprise for the purpose of enabling business officials such as executives, managers and analysts to make better and more rapid decisions. Parr Rud [4] defined BI as a collection of methodologies, theories, architectures and technologies used to convert data into worthwhile information essential for enterprises to improve the economic activities that they are carrying.

Howson [5], in 2013, gives another definition to the concept of business intelligence. She said, business intelligence is a technology that allows people from all levels of an organization to access, interact and process data for an enterprise's management, to improve its performance, to discover new opportunities and to work more efficiently.

BI can be defined as the process to get (digital) information about the company's entire business so that it can be used to provide the so-called competitive advantage [6].

Dresner [7] has defined BI as "knowledge gained through the access and analysis of business information". Some examples of tools and techniques in BI are OLAP (online analytical processing), data mining and analytics, queries and reports, and performance monitoring dashboards. The figure below, Figure 1, shows a typical BI architecture.

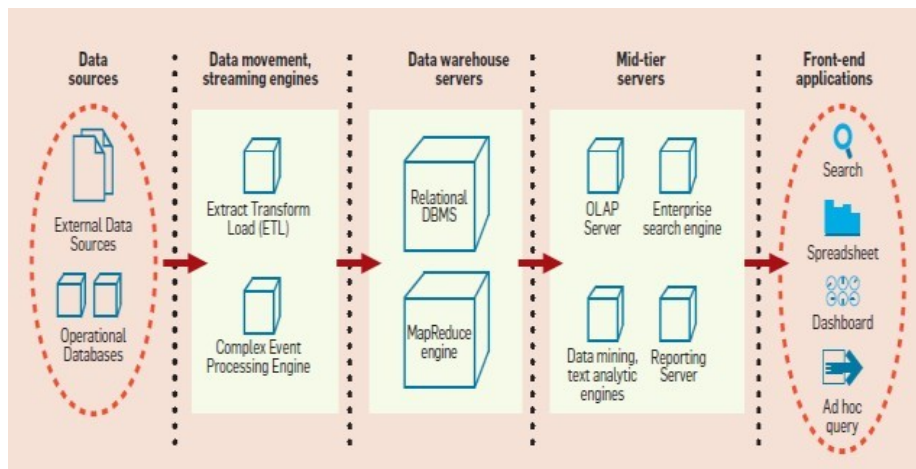

Figure 1: Typical business intelligence architectures. Source: [3]

Vajirakachorn et al [8] also talks about Blas one of the application areas of information technology that is becoming important in supporting business decisions. The concepts of business intelligence open the door to opportunities to integrate platforms to handle complex, unstructured data from emerging data sources and emphasize the analytical process of turning the data into actionable strategies for better business decisions [9].

\section{SMEs in Malaysia}

SMEs have the potential to contribute substantially to the economy and can provide a strong foundation for the growth of new industries as well as strengthening the existing ones, for Malaysia's future development. Developing stronger SMEs require major changes in the manufacturing sector, as SMEs make up over $90 \%$ of the Malaysia's manufacturing sector [10].

According to the SMEs Corp Malaysia [11], 98.5\% of the businesses that are established in Malaysia are SMEs and they are spread out across all sectors. In Figure 2 it can be seen how they are cut out across all sectors by size.

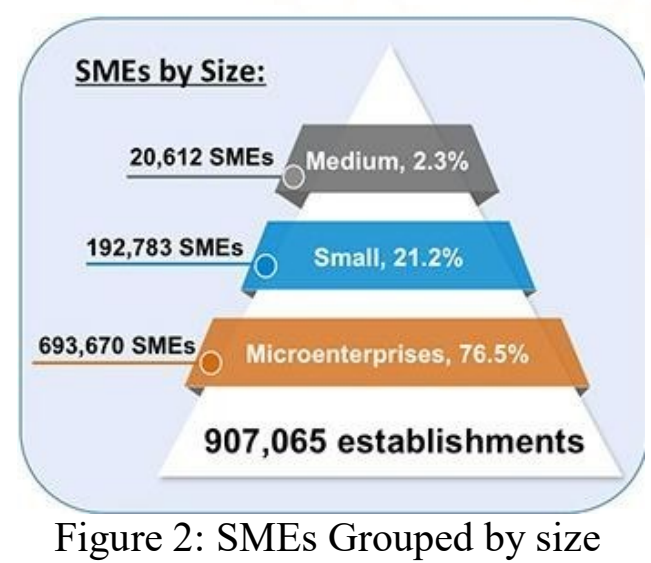


(http://www.smecorp.gov.my/index.php/en/policies/2 015-12-21-09-09-49/sme-statistics)

However, when the division is done by sector, it can be noticed that the services sector is the largest sector is the services sector taking $89.2 \%$ which is roughly 809,126 as of 2016.

In addition, as it is generally known by the public, IT is often offered as a service hence, it is logical to include it in the number mentioned above. As the number of IT based SMEs grows, the competition will get stiffer that is why BI systems become a necessity. Instead of waiting for the time when the business desperately needs BI, it is best to equip its self with small steps. "Being forewarned is being forearmed."

Figure 3 shows the division by business sector in Malaysia.

\section{SMEs by Sector:}

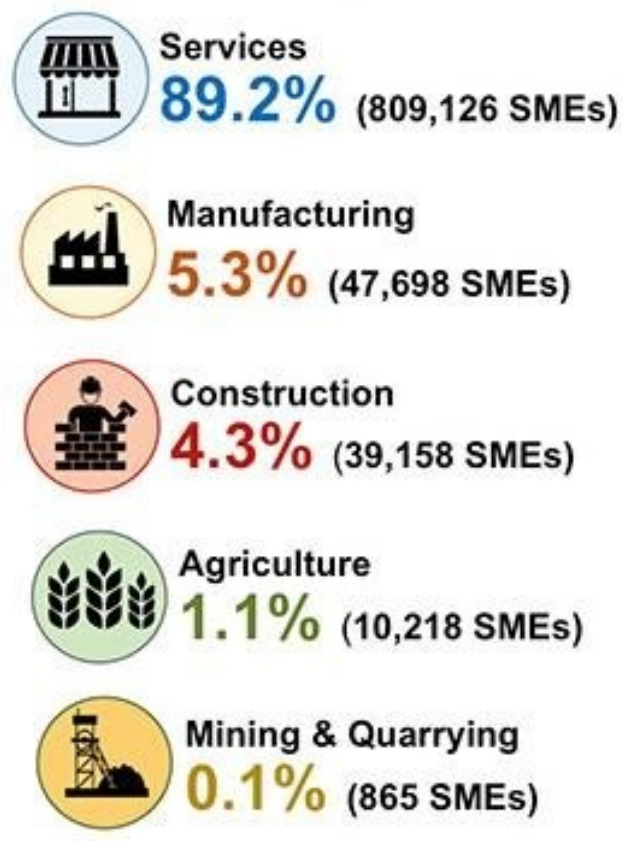

Figure 3: Division by sector (adapted from smecorp.gov.my)

\section{BI and IT-Based Small-Scale Enterprises}

Initially, BI was developed for large-scale industries because of the huge amount of information it collects and use. However, there are features of BI that are beneficial to small-scale enterprises. It is because of this premise that the usage of BI among small and medium enterprises will be expected to increase in the future. The reason is because software vendors would begin to focus on this market segment and also the current technological trends are going towards small business usage. Horakova and Skalska [12] has given an example of a BI solution implementation in a small company showing how the multidimensional analytical data model and other similar applications and systems can be designed, developed and implemented for an SME.

Dresner Advisory Service [7] reported that BI is fit for SMEs. "Through a confluence of need, awareness and product focused on SME needs, they appear to be rising to the occasion and taking advantage of the opportunity that BI presents." Five to 10 years ago, it is not like this. Today, SMEs not only realize the benefit of BI, they also report greater fulfilment than the large enterprises. Dresner also believes that smaller organizations better understand businesses, their customers and what BI will be able to offer for them. Because of this they can act quickly thereby achieving more meaningful results."

SMEs did not report the same length of experience as larger enterprises: About one-third of small and more than 20 percent of mid-sized enterprises reported having a year's experience or less with business intelligence. This is perhaps not surprising, given that BI vendors initially focused on larger enterprise customers in client- server environments. The nimbleness and flexibility of business intelligence delivered as software-as-a-service (SaaS) for SMEs makes more and smaller deals a reasonable value proposition, as opposed to fewer slam dunks.

"Of course, larger enterprises continue to generate the big deals, but they are far fewer in number than SME deals," says Dresner. "SME is a growth segment for vendors which most -- if not all -- recognize and are investing in. Getting to these SME opportunities requires a different sales model as they tend to be lower value deals. So, a strong channel program is often needed."

The economy of Malaysia has significantly benefited on the exports of electrical and electronics products. The mid-1990s has seen that more than 50 per cent of Malaysia's exports have been electrical and electronic products. And now in the advent of IT-based products, it has upgraded to electronics and IT products. Quality- wise, the products are deemed mostly mature with relatively low value-added [10]. This percentage has increased due to the popularity of electronic gadgets and integration of IT and communications technology. This is also the time that 
emerging technologies are adopted in this area of business.

The acquisition of a BI for business solutions may be difficult but the benefits are worth it. Similar to large corporate businesses the list of benefits that BI offers to SMEs is quite long but the core benefits are the following:

\section{Empowering employees-}

in layman's terms, this if selecting a solution that empowers your employees to become an analyst in your business. Few of the SMEs have the capability of hiring 'Analysts'. It is vital to find a key the is simple enough to fathom as well as simple enough for a new business man to manipulate. Early iteration of BI software demanded a comprehensive knowledge of programming which is rather counter intuitive for an SME with real time analysis of its own data. For a business to grow activities such as cash flow and attaching new practices that could welcome customers are what an entrepreneur would be doing. Clearly writing computer code does not welcome customers. Today, BI tools practically don't require programming knowledge to generate dashboards. Such BI solutions can help save time in examining raw data considering that they have a built-in analytics tool.

\section{Being visually appealing-}

The human mind is designed in such a way that if it perceives something that looks good, it shows appreciation. This applies to various forms of information as well. What this means is, a business, in this case an SME, should strive in making its data presentable and interesting so that investors as well as customers can fully understand the analysis. Doing so is not an easy task but it is something an SME can handle.

One thing that need to be considered while creating visualized content is that it has to be as accurate as the raw data, in lay man terms it means it has to be $100 \%$ precise with what your trying to get across. "This is why it is necessary to look for solution that will aid in the making of visual representations of the data easily such as using charts and trend line." [13]

\section{Software dynamism and efficiency-}

this is a must have skill for an enterprise. After all, evaluating your audience is a core factor of business analytics and the key reason of using BI tools. The early models of BI software required a team of IT experts to excerpt the collected data and leaving the analysts waiting for the process to finish.

Transforming the data into powerful bits of information it required at least half a month before it is delivered to the owner of the business. In addition, the longer the IT team takes to extract the data, the less effective the data will be. This is because the market is on a constant change with varying consistency.

With the implementation of a BI system, target marketing can be done even faster. It would enable the enterprise to distinguish what the needs of the customers are and what effects the new advertisements has on them or even knowing what colour is preferred for a certain product. This is the kind of information that is looked-for in the analytics progression.

According to SMEcorp Malaysia, a master plan has been put in progress to improve the development of SMEs. Beginning from the year $2012-2020$.

The figure below, Figure 4, shows the goals that to be archived by the year 2020

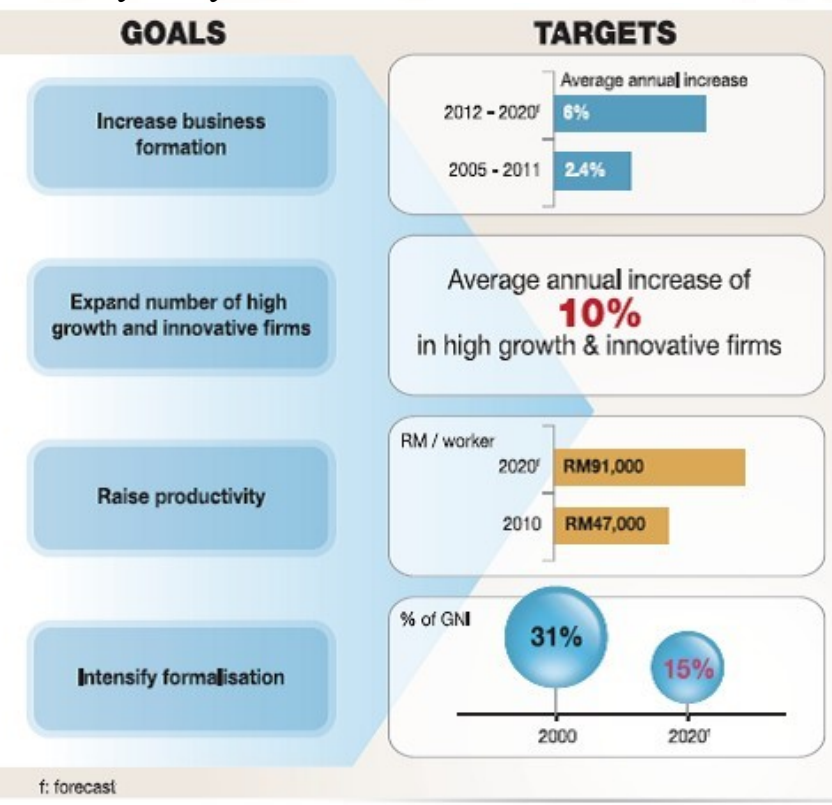

Figure 4: SMEcorp Mastaplan Goals (adapted from: http://www.smecorp.gov.my)

\section{Conclusion}

The prevalence of data and information is astounding. People's hand phones create data every time they use them. Whenever one uses the web, weblogs that are created would leave a data trail. The applications and 
systems being used now to capture, collate, store and analyse these data are getting better and speedier while data are increasing. New technologies are becoming more powerful. The challenge now is for SMEs to ve able to realize how they can use these technologies to innovate and enhance their products and services. To increase SME's leverage, they should consider being upgraded. Especially for ITbased business, the use of updated technology may well elevate how they do business by patronizing that they themselves are selling or giving service for.

IT-based SMEs in Malaysia play a big role in the economy. It is but right for these businesses to have support from high end technologies such as business intelligence, which in the past has been confined to large businesses only. But the present times have shown that small-scale enterprises also use and produce large amount of information just like large companies, although not in the same way. Business intelligence has evolved into a technology that is not exclusively for large corporations but also for other types such as small-scale enterprises.

This paper proposes a guideline for IT-based smallscale enterprise for adopting business intelligence. A more thorough research on the topic is recommended to learn factors and constraints on applying business intelligence to SMEs. Other areas like which tools are more appropriate to small-scale enterprises.

\section{References}

1. O. Grabova, \& J. Darmont, \& J. H. Chauchat, \& I. Zolotaryova,. (2010). Business Intelligence for Small and Middle-Sized Enterprises. SIGMOD Record. 39. 39-50.

2. L. King, "How Business Intelligence Helps Small Businesses Make Better Decisions", HuffPost, 2017. [Online]. Available: https://www.huffingtonpost.com/laiza-king-/howbusiness-intelligence_1_b_11207388.html. [Accessed: 20- Oct- 2017].

3. S. Chauduri, U. Dayal, V. Nasarayya, "An overview of business intelligence technology". August 2011, Communications of the ACM, VOL. 54, NO. 8, DOI :10.1145/1978542.1978562
4. O. Parr Rud, Business Intelligence Success Factors - Tools for Aligning Your Business in the Global Economy, John Wiley \& Sons, 2009.

5. C. Howson, Successful Business Intelligence, McGraw-Hill/Osborne, 2013

6. Malhotra, Y, Knowledge Management and Virtual Organizations, Idea Group Publishing, USA, 2000 .

7. Dresner Advisory Services (2016) Small and Midsized enterprise business intelligence market study. Wisdom of crowds series, September 2016.

8. T. Vajirakachorn, J. Chongwatpol, Application of business intelligence in the tourism industry: A case study of a local food festival in Thailand, Tourism Management Perspectives. www.elsevier.com/locate/tmp

9. G. Phillips-Wren, Iyer, L. S., Kulkarni, U., \& Ariyachandra, T. (2015). Business analytics in the context of big data: A roadmap for research. Communications of the Association for Information Systems, 37(1), 448-472.

10. M. W. Khan, "An Overview of Small and Medium Enterprises in Malaysia and Pakistan: Past, Present and Future", Scenario Business and Management Horizons 2014, Vol. 2, No. 2, ISSN 2326-0297

11. Smecorp.gov.my. (2017). HOME. [online] Available at: http://www.smecorp.gov.my/index.php/en/ [Accessed 7 Nov. 2017].

12. M. Horakova, H, Skalska (2013) Business Intelligence and Implementation in a Small Enterprise, Journal of Systems Integration, Vol 4, No 2 (2013)DOI: http://dx.doi.org/10.20470/jsi.v4i2.159, ISSN: 1804-2724

13. Goewey, B., 2015. How SMEs Can Benefit From Business Intelligence. [Online] Available at: http://www.datamensional.com/how-smes-canbenefit- from-business-intelligence/ [Accessed 01 November 2017]. 